\title{
CONSTRUCTABILITY IN INDUSTRIAL PLANTS CONSTRUCTION: A BIM-LEAN APPROACH USING THE DIGITAL OBEYA ROOM FRAMEWORK
}

\author{
Daniel Luiz de Mattos NASCIMENTO ${ }^{\mathrm{a}, \mathrm{c}}$, Elisa Dominguez SOTELINO ${ }^{\mathrm{a}}$, \\ Thiago Pires Santoloni LARAc, Rodrigo Goyannes Gusmão CAIADO ${ }^{\mathrm{b}}$, Paulo IVSONc \\ ${ }^{a}$ Department of Civil and Environmental Engineering, Pontifical Catholic University of Rio de Janeiro, \\ Marquês de São Vicente Street, 225, 22430-060, Rio de Janeiro, Brazil \\ ${ }^{b}$ Department of Post-Graduation in Sustainable Management Systems, Federal Fluminense University, \\ Passo da Pátria Street, 24210-240, Niterói, Brazil \\ ${ }^{c}$ Tecgraf Institute, Marquês de São Vicente Street, 22451-900, Rio de Janeiro, Brazil
}

Received 04 May 2017; accepted 04 Sep 2017

\begin{abstract}
One of the main problems the construction industry faces is the high cost and slow execution time due to inadequate planning, which results in poor use of human resources. A common solution for reducing time and costs is the adoption of prefabricated components (prefabs). This paper proposes a novel methodology for interdisciplinary management of construction projects by integrating Building Information Modeling (BIM) and Lean Thinking to improve the production planning and control of pipe-rack modules in an industrial facility. The article first presents a literature review to assess the key synergies between BIM and Lean Thinking. These led to the development of a new integrated work methodology named Digital Obeya Room. This model focuses on the required workflows, the analysis of collected data, and the visual management of construction planning and control. A real-world empirical study in the Oil and Gas industry evaluated how the newly devised practices could improve prefabrication and preassembly planning. The proposed methodology was capable of reducing the welding-time in $8.7 \%$ related on global prefabrication average in construction projects from Fails Management Institute (FMI) prefabrication report survey 2017.
\end{abstract}

Keywords: BIM, construction projects, interdisciplinary management, Lean Thinking, PDCA, Obeya Room, constructability, prefabrication, production planning.

\section{Introduction}

Employing constructability in the beginning of Engineering, Procurement and Construction (EPC) contracts, results in a cost reduction between 6 and 23 percent as well as a significant reduction in the lead-time (Construction Industry Institute 1993). Othman and Ahmed (2011) state that constructability should be applied as early as possible because it directly affects the cost of the project. In fact, Russell et al. (1992) concluded that incorporating the knowledge of constructability in the design phase can generate savings of approximately $10 \%$ in lead time. The Construction Industry Institute (1987) defines constructability as "the optimum use of construction knowledge and experience in planning, design, procurement, and field operations to achieve overall project objectives". Kifokeris and Xenidis (2017) note that "constructability indeed encompasses methodological and decision-making aspects of indicative planning and operations performance evaluation, value engineering, knowledge management, cost/benefit analysis, total quality management, [...] the six concepts of the total building performance framework (spatial performance, acoustic performance, visual performance, indoor air quality, thermal performance, and building integrity) [...]". Constructability analysis is employed during the detailed engineering design phase is in progress, when 3D models are used with great frequency (e.g. simulations of the construction and assembly sequencing in a virtual environment).

According to Hijazi et al. (2009) and Papadopoulos et al. (2017), due to its parametric nature, the use of the Building Information Modeling (BIM) methodology provides designers with the freedom to search the best alternatives for project implementation. By simulating the construction project in a virtual environment, the combination of BIM with constructability concepts contributes to achieve overall objectives in terms of time, cost and quality. However, Arayici et al. (2011) found that construction companies are still facing barriers and challenges to BIM adoption. This is mainly because there is

Corresponding author: Daniel Luiz de Mattos Nascimento

E-mail:danielmn@puc-rio.br 
no clear orientation or effective practical studies to help companies improve their capabilities to use BIM. The lack of such capabilities prevents improvements on productivity, efficiency, and quality.

The constructability study can bring practical experience if used at the beginning of planning and engineering (Jergeas, Van Der Put 2001). The traditional separation between the engineering and construction at the beginning of the project must be reduced by approaching teams from these different areas. This philosophy requires a culture change, analyzing the differences and common points between engineering and construction, making this a permanent and irreversible transformation. Nowadays, many companies have begun to apply the constructability practice, but they do not refer to it by this name. For these organizations, constructability is simply good project management. Jupp (2017) points out that, in the past decade, the use of BIM models for constructability analysis and for monitoring onsite activities during construction has increased. From this facts, can be stand out that BIM for construction planning, scheduling and production control improve the management of construction, safety, workspaces and decrease waste.

Within this context, this paper proposes an innovative framework called the Digital Obeya Room (DOR) for construction management. This framework is based on the integration of BIM and Lean Thinking concepts and tools in the Plan, Do, Check and Act (PDCA) cycle. The framework was evaluated through a real-world case study on the production planning and control of pipe rack modules, where the new methodology brought significant gains in relation to welding lead-time and carbon emissions.

\section{Research method}

Through the exploration of the interplay between BIM and Lean concepts as applied to industrial plant construction projects, this work has the objective of answering the following question: How BIM functionalities and Lean thinking principles can be applied in the modularization design and construction of pipe racks in industrial plants? It also seeks to answer two secondary questions: What is the gain in the welding lead-time when BIM and Lean are combined with constructability concepts and what is the environmental impact of this interaction?

The approach adopted in this work is exploratory in nature because it aims at bringing together the most relevant information of BIM functionalities and Lean principles available in the literature. It is also descriptive because it seeks to reveal how information can be presented to project managers for decision-making purposes, and how to replicate these methodologies and technologies in similar environments. As a research strategy, according to Voss et al. (2002) and Childe (2011), three approaches were used: exploration, theory-building and, at last, comparison. The exploration stage consists of applying the Lean principles and BIM functionalities to in-
Step 1: Literature review of BIM and Lean

Step 2: Identification of synergies between BIM and Lean

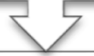

Step 3: Proposition of Digital Obeya Room framework

\section{5}

Step 4: Empirical study to validate the proposed framework

Step 5: Analysis and description of the main contributions

Fig. 1. Methodological research process

dustrial plant construction. The second strategy, theorybuilding, was responsible to bring these concepts, mix them and propose the new solution, the Digital Obeya Room (DOR). Finally, the lastly stage consists of comparing the empirical results obtained with those reported in the literature. Figure 1 shows the sequence of steps taken throughout the development of this research.

In the first two steps of the methodology, a thorough literature review of Lean principles and BIM functionalities was carried out in order to find BIM-Lean synergy points. The understanding of BIM \& Lean approaches allowed the analysis of similarities and generated questions about their applications, knowledge and aspects relevant to the construction industry. The third step of the research involved the proposal of the Digital Obeya Room, in which the key functionalities of BIM, principles of Lean and the synergies between these approaches were evaluated and mapped within PDCA for continuous improvement of the engineering process. The fourth step consisted of an empirical study of a real-world industrial plant construction project, in which the proposed DOR Framework was analyzed by experts. These experts had more than ten years of experience in industrial construction and knowledge of both BIM and Lean concepts. This analysis occurred through collaborative sessions in order to improve the sequencing and work-package viability.

This step helped to validate the framework. Moreover, in this step a discussion of results was carried out with the objective of comparing the state of the art with expert's opinions. Finally, in the fifth stage a synthesis of the main contributions were made and a proposal was developed containing final considerations, practical implications of the research and suggestions for future studies. Triviños (1987) states that case studies can also be performed for quantitative analyses, however, he highlights the need for data collection to produce reliable analyses. In the present research work, the quantitative data is collected from a 3D BIM project, which provides a report containing the 
quantity of piping welds and its specific characteristics and materials, describing how these data were used in the modularization of pipe racks.

The study can be considered valid insofar as the data were obtained from different procedures (literature background, proposed model and empirical study). This enables a triangulation that helps reduce researcher subjectivity, while also increasing the quality and precision of the results (Runeson, Host 2009; Yin 2004).

\section{Literature background}

Building Information Modeling and Lean Thinking have been topics of several research works for many decades. The following subsections focus on recent results regarding BIM functionalities and Lean principles, highlighting their potential synergies towards improving the construction project management.

\subsection{Synergies between BIM and Lean}

Olatunji (2011) observes that BIM has been associated with the development of Lean approaches for project management. This is especially true since BIM provides frameworks and technologies for advanced collaboration and information sharing. As reported by Koskela (1992) and Sacks et al. (2010), even though the concepts of Lean Construction and BIM are independent and separate, there are synergies between them that extend beyond the maturity of their contemporary approaches. However, their simultaneous adoption in construction can be a potential source of confusion when it comes to assessing their impact on efficiency. Lean Construction is a conceptual approach for project management, while BIM is a transformational information exchange methodology.

Clemente and Cachadinha (2013) used Value Stream Mapping (VSM) to identify activities that add value and associate them with the principles of Lean Thinking to each BIM functionality. According to interviews with the workers involved with such projects, many improvements were perceived such as: better coordination, ease of visualization compared to the traditional methodology that uses 2D documents, better communication to solve challenges, and greater security in execution. Dave et al. (2015) state that a conceptual analysis of Lean Construction and BIM indicated positive synergies throughout the life cycle in the Architecture, Engineering, Construction and Owner-Operated (AECOO) sector. Interviews with experts and potential users in the industry have found that the use of BIM is limited to physical interference (Clash Detection) and 4D planning. In addition, they have identified which Lean Production management tools depend on the manual collection of information.

However, according to Sacks et al. (2010), the largest research effort in the area of construction visualization focuses on the design phase (3D) and construction planning (4D). The construction management effectively requires this type of tool, since the complexity of construction makes it very difficult for participants to have a clear mental picture of what is happening and what needs to be done. The authors demonstrate how 3D models can be used to monitor essential aspects of planning and control in flow management. Visualization of the risks associated with the planned tasks allows construction managers to know where to efficiently direct resources, train teams and/or change short-term planning.

Similarly, Hamdi and Leite (2012) state that the main relevance of BIM is the possibility of retrieve organized, defined and interchangeable information, not just 3D modeling. Since the BIM process promotes transparency of information, it becomes an ideal tool for effective management. Within this context, Becerik-Gerber and Rice (2010) describe how the information can be used to promote synergism between BIM-Lean on the three projects that they analyzed. These authors obtained benefits by prioritizing what adds greater value to the customer, while significantly reducing waste in the form of time, material and cost. The study points out that the implementation of BIM in the industry will raise Lean Construction.

Sacks et al. (2010) describes efforts to explore the synergy between BIM and Lean. One of the efforts incorporated Lean principles with Computer Aided Visualization Tools (CAVT) emphasizing value generation during the design phase (Rischmoller et al. 2006). The feasibility of the relationship implies that any organization / project in the construction industry on a Lean journey should consider using BIM to improve its results and companies using BIM should ensure that their adopted process contributes to the maximum to leave their processes Lean. Likewise, Dave et al. (2015) observed the synergic potential of Lean Construction and BIM throughout the life cycle of a construction project. Even though these synergies were studied in the implementations of individual designs, there is no systematic exploration strategy, and there is a lack of integration technologies capable of materializing these synergies.

\section{Digital Obeya room}

Obeya is a Japanese word meaning "large room". As stated by Morgan and Liker (2006), the Obeya room concept was first created by a Toyota executive to help to better coordinate a complex engineering project. To implement this concept, several A3 sheets of paper are hung up all over the walls of a large meeting room to describe the different points of view of the project's members of design and business teams. Hence, each participant could have easy access to information and form a better understanding of each other's opinions about the project, in the context of visual management and continuous improvement (Terenghi et al. 2014).

The Obeya rooms, like many other Lean practices, have proven to be very successful in optimizing the value stream of cooperative management processes. The rooms help to make decisions faster (Javadi et al. 2013), provide the basis for significant cuts in waste (Terenghi et al. 
2014), and lower the time, space and organizational barriers (Oosterwal 2010). Participants can listen actively to the concerns of other teammates and gain a deeper awareness of problems, thus accelerating the development of solutions. Based on a big room by means interdisciplinary management in the workflows of PDCA cycle, the Obeya Room steps and destinations, involve experts belonging from each department of a company such as construction and assembly, procurement, operated, maintenance and design. The Visual Management is used in order to (1) analyze facts and/or data, (2) discuss and (3) take key decisions (Andersson, Bellgran 2009; Blankenburg et al. 2013; Bruch 2012; Lindlof, Soderberg 2011).

The DOR framework proposed in this work aims contribute to interdisciplinary project management in the construction industry. This model focuses on the workflows required, the analysis of collected data, and the visual management of production planning and control. The new approach stands out by the use of BIM technologies for system integration, data analysis through indicators combined with 3D visualization for continuous and incremental improvement based on the PDCA cycle. Unlike current methodology, where systems are isolated, this framework proposes an integration of several engineering systems to provide access to diverse information. All the information necessary to manage the project should be contemplated in the model to viewed in the "Digital Obeya Room" environment, where the PDCA cycle runs. Figure 2 shows the proposed framework.

Since the goal of the BIM methodology is to build a representative error-free model, Hickethier et al. (2011) points out that the use of Plan-Do-Check-Act cycle is completely adaptable for use with BIM (e.g., BIM users may follow the PDCA cycle to continuously improve their BIM development process through learning loops). Therefore, it is natural to propose an integration of BIM and Obeya room concepts, since both of them use the PDCA cycle for continuous and incremental improvement of work processes.

On this proposed DOR framework, all the information is extracted, transformed and loaded into an integrated database. Afterwards, the data is analyzed, consolidated in indicators and linked to 3D visualizations. The following steps describe the adopted workflow for continuous improvement and the requirements of each activity:

- PLAN: The balancing opportunities (design, materials, equipment's, work fronts), and priorities (deadlines, dependencies, resources, costs) with the goal of promoting a pulled production system of the activities, seeking to achieve an optimal production level. In this step the production capability and work package practicability (Workface Planning) are assessed;

- DO: The control of task execution considering supply, production, quality, health, safety, and environment;

- CHECK: The analysis of results and metrics relative to: physical and financial advances, key performance indicators, difficulties and problems;

- ACT: The analysis of impacts on schedule, while updating and refining priorities. The goal here is to select the best opportunities based on the relationship between expected versus actual results.

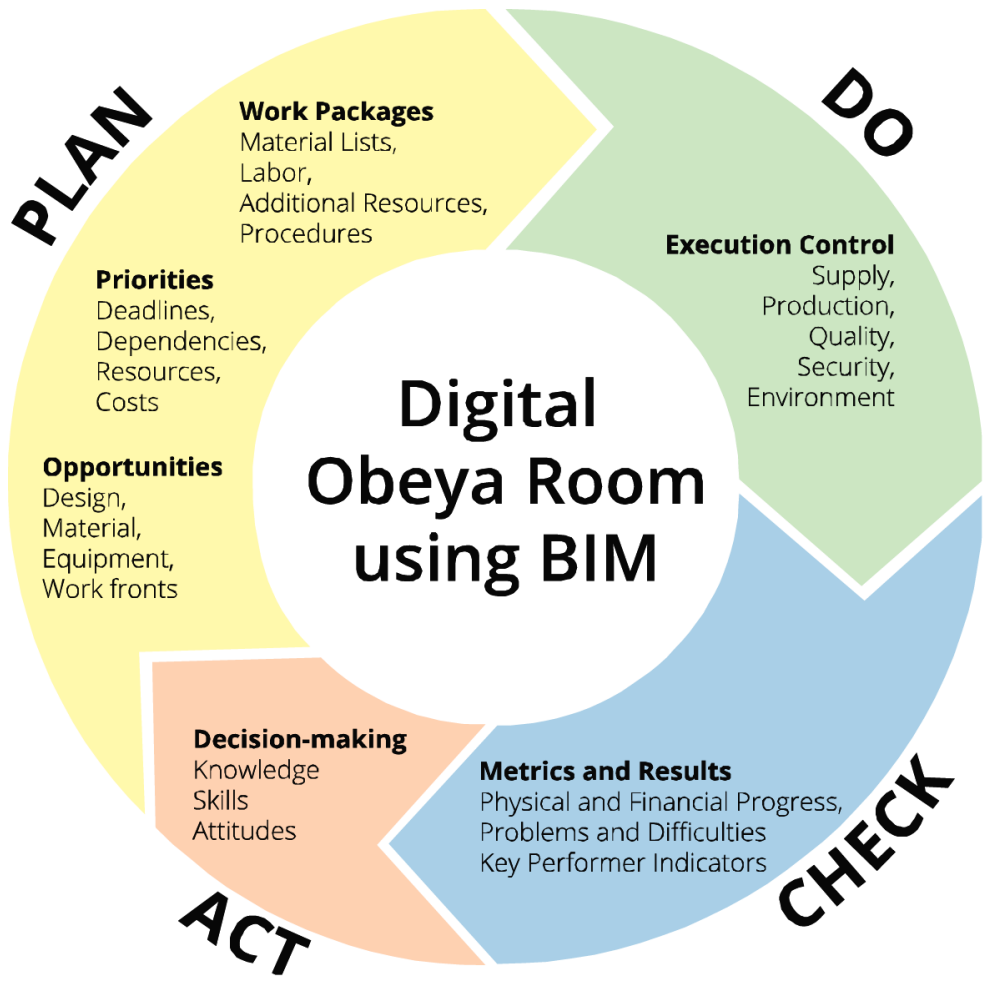

Fig. 2. Digital Obeya room - Information flow using the proposed framework 
- In all of the previous steps, the 3D visualization system simulates and analyzes work plans and contingencies in a visual and collaborative manner. All stakeholders are involved in meetings to define actions within the PDCA cycle, using the 3D visualization as a way to monitor tasks on all steps of continuous improvement. The destinations that take place in the Digital Obeya room are listed below:

- To define clear and visual goals according to the integrated engineering data and 3D visualizations;

- To verify availability and optimal quantities of materials and people to properly allocate resources;

- To enable information integration and democratization for better interdisciplinary synergy;

- To share essential planning information with the construction companies;

- To encourage useful feedback by different stakeholders with diverse points of view;

- To analyze constructability, confirming the best assembly sequencing.

In this manner, it is possible to level the available resources by physical areas and to manage work and material flows. The 3D visualization system provides functionalities for constructability analysis, determining and validating work packages prior to production. These, in turn, guide supply management to verify storage availability and logistics, minimize materials movement and apply FIFO (first-in, first-out) to supply the construction work areas. Within this context, the Lean Mizusumashi technique according to Ichikawa (2009) is used to define paths and routines of material management so that the workforce can focus solely on the assembly tasks.

\section{Empirical study}

The proposed DOR Framework was applied during the construction of an oil refinery in Brazil between April 2013 and July 2015. Key experts from several engineering disciplines followed the PDCA cycle in collaborative analysis sessions to define the best assembly sequencing and work-package viability for prefabricated modules. Prefabrication and preassembly techniques are widely used in oil and gas projects. Modularization is an important strategy that is typically addressed during conceptual planning. Preassembly should begin as soon as possible, preferably at the engineering phase ( $\mathrm{O}^{\prime} \mathrm{Connor}$ et al. 1987). In the exploration and production segment, the concept of modularization is widespread. In refineries and petrochemical plants, the adoption of this technique has been growing significantly to reduce lead-time and $\mathrm{CO} 2$ emissions.

The benefits with the use of prefabrication and prefabricated normally include an increase in productivity and possibility of sequential activities in parallel. In addition, the work can be carried out in the construction site with better conditions of access and quality control, reducing the need for scaffolding (O'Connor et al. 1986). Module assembly follows an appropriate infrastructure, minimizing work at height and risks to personnel. However, this concept has some limitations. According to the Construction Industry Institute (1987), during the engineering phase, the weight limitations of the modules for lifting and wind conditions for assembly must be studied. It should also be foreseen the handling capacities and accessibility.

In this study's project, the strategy to modularize and make preassemblies, whenever feasible, was adopted. All services that required excavations, such as drains, were anticipated to allow the drives and the positioning of cranes for lifting the each module. Structures for pipelines (pipe racks) and cable trays were designed in two parts, enabling activities to occur in parallel. After completion of the preassembly separately, the structures were put together before the final lifting. The DOR framework brought several benefits to the regular planning sessions:

- Data collection of engineering systems with opportunities of daily production in an automated way from technical lists of structures, pipelines and electrical systems;

- 4D planning analysis performing constructability studies and determination of the ideal assembly sequencing;

- Analysis of the integrated data by Key Performance Indicators (KPIs);

- Use of the 3D viewer to identify and determine clearly task priority;

- Managing the supply chain according to construction priorities;

- Using functionalities of BIM and principles of Lean Thinking for workflow PDCA cycle.

From the integration between BIM and Lean principles, it was possible to verify the accordance between design, supply, and work fronts prior to the execution. This enabled better assembly sequencing, considering several variables, as well as the expert opinions in a visual representation of different scenarios.

The Digital Obeya room was applied both in weekly and monthly meetings to define the work programming for the following month. Teams from design, supply, planning, construction, transportation, logistics, quality, and kaizen leadership were involved. Decisions about assembly sequencing and action plans were made democratically after hearing everyone's opinions. By integrating piping fabrication data and the 3D BIM project, it was possible to create a direct link between the design and the fabrication to start manufacturing items for the monthly work schedule.

As illustrated in Figure 3, the dimensions of each module were delimited using volumes in the 3D BIM model. For each module, the stakeholders analyzed weight to allocate proper cranes, weld estimation, fabrication strategies, transportation and assemblage. The modules were (1) preassembled next to the concrete structures and (2) raised to the final destination. This operation was carried out for each module. 


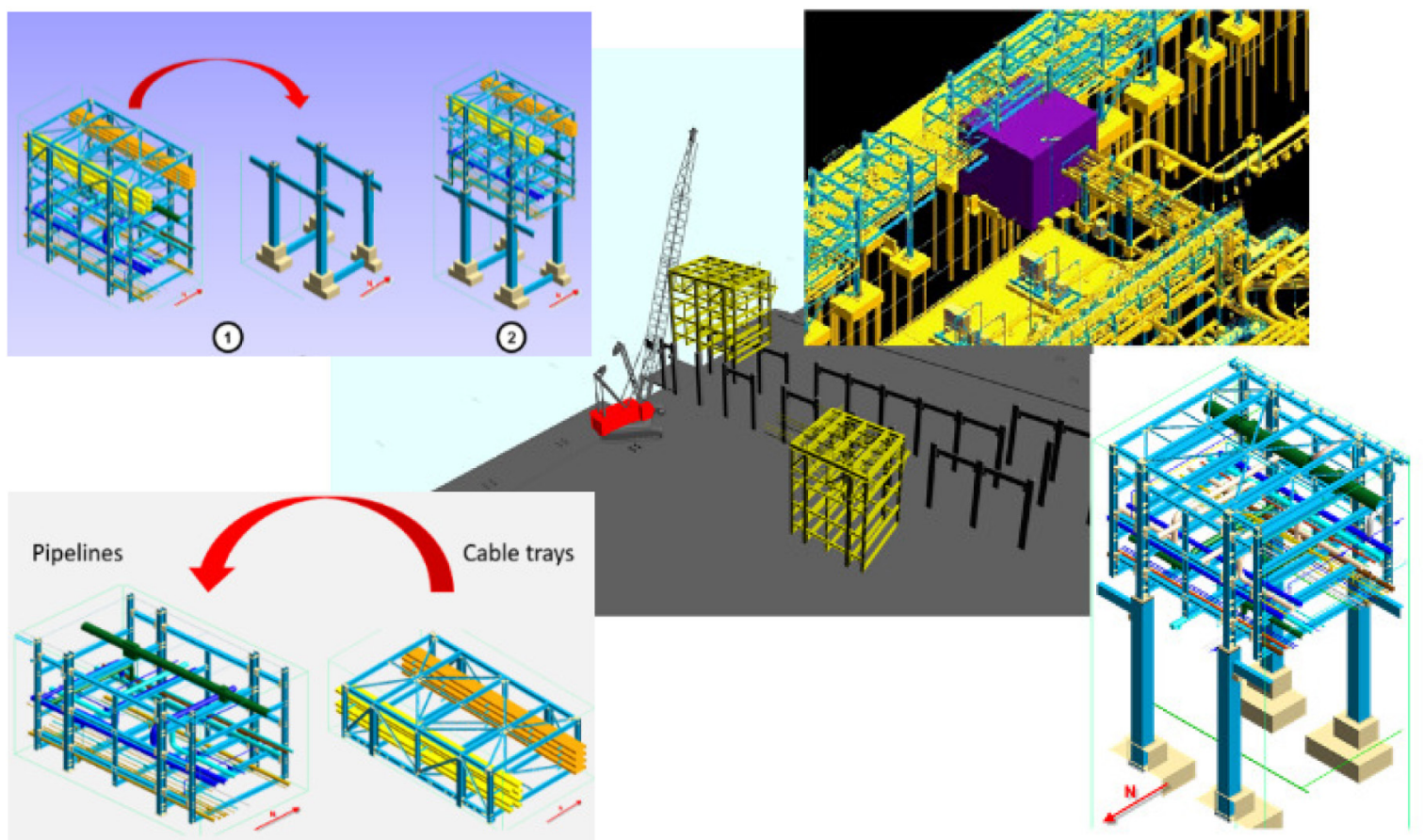

Fig. 3. Rapid generation and evaluation of construction plans

Figure 3 demonstrates the three steps to select the sample of each module, it prepares the interdisciplinary component work package, and it shows how to transport the pre-assembled parts to the pipe rack. To mitigate the adverse weather situations and improve the productivity, a temporary cover was built on site. In this tent, the pipe rack modules were separated and pre-assembled. Workers were exposed to fewer dangerous situations, since the pre-assembly of the modules were performed on the ground, avoiding the risk of falling. In the end, the decision-making process of the DOR Framework improved work modularization and increased the number of prefabricated welds. The quantity of welds from the 3D BIM project is illustrated in Figure 4.
According to Kardec and Simonsen (2004), a weld performed in the field involves 4 times more man-hours than a prefabricated weld. Hoover et al. (2017) states that on average, $35 \%$ of the total project items are prefabricated and preassembled. In this empirical study, $43.55 \%$ of welds were prefabricated. Eqn (1) was used to evaluate the time required to perform all welds in both cases (documental and empirical study):

$$
t=n \times\left(P_{\text {prefab }} \times t_{\text {prefab }}+P_{\text {field }} \times t_{\text {field }}\right),
$$

where: $t$ - time to perform all welds; $n$ - total of project welds; $P_{\text {prefab }}$ - percentage of prefabricated welds;

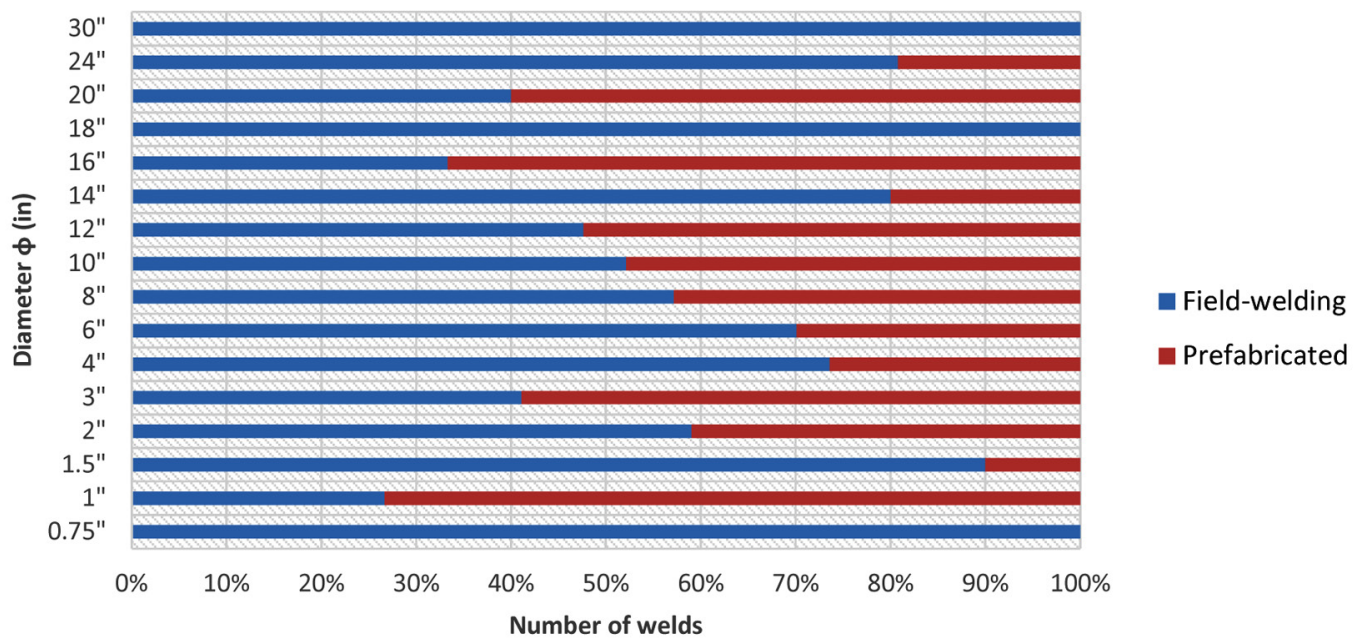

Fig. 4. Comparison of the number of welds by diameter between field-welding and prefabricated-welding from the 3D BIM project 
Table 1. Quantity of welds by diameter in comparison between field-welding and prefabricated from the 3D BIM Project

\begin{tabular}{ccccccc}
\hline Diameter & $\begin{array}{c}\text { Number of } \\
\text { welds }\end{array}$ & Field-welding & Prefabricated & $\begin{array}{c}t_{E S} \\
\text { (time unit) }\end{array}$ & $\begin{array}{c}t_{F M I} \\
\text { (time unit) }\end{array}$ & $\begin{array}{c}\text { Time saving } \Delta \mathrm{t} \\
(\%)\end{array}$ \\
\hline $0.75 "$ & 12 & $100 \%$ & $0 \%$ & 48 & 35 & $-0.2 \%$ \\
$1 "$ & 15 & $27 \%$ & $73 \%$ & 27 & 44 & $0.3 \%$ \\
$1.5 "$ & 10 & $90 \%$ & $10 \%$ & 37 & 30 & $-0.1 \%$ \\
$2 "$ & 183 & $59 \%$ & $41 \%$ & 507 & 540 & $0.5 \%$ \\
$3 "$ & 382 & $41 \%$ & $59 \%$ & 853 & 1127 & $4.6 \%$ \\
$4 "$ & 352 & $74 \%$ & $26 \%$ & 1129 & 1038 & $-1.5 \%$ \\
$6 "$ & 87 & $70 \%$ & $30 \%$ & 270 & 257 & $-0.2 \%$ \\
$8 ”$ & 322 & $57 \%$ & $43 \%$ & 874 & 950 & $1.3 \%$ \\
$10 "$ & 71 & $52 \%$ & $48 \%$ & 182 & 209 & $0.5 \%$ \\
$12 "$ & 481 & $48 \%$ & $52 \%$ & 1168 & 1419 & $4.2 \%$ \\
$14 "$ & 20 & $80 \%$ & $20 \%$ & 68 & 59 & $-0.1 \%$ \\
$16 "$ & 18 & $33 \%$ & $67 \%$ & 36 & 53 & $0.3 \%$ \\
$18 ”$ & 7 & $100 \%$ & $0 \%$ & 28 & 21 & $-0.1 \%$ \\
$20 "$ & 20 & $40 \%$ & $60 \%$ & 44 & 59 & $0.2 \%$ \\
$24 "$ & 26 & $81 \%$ & $19 \%$ & 89 & 77 & $-0.2 \%$ \\
$30 "$ & 33 & $100 \%$ & $0 \%$ & 132 & 97 & $-0.6 \%$ \\
\hline
\end{tabular}

$t_{\text {prefab }}$ - time required to perform a prefabricated weld; $P_{\text {field }}$ - percentage of field welds; $t_{\text {field }}$ - time required to perform a field weld; $t_{\text {field }}=4 \times t_{\text {prefab }}$.

Comparing the quantitative results of the empirical study with the results from the survey by Hoover et al. (2017), it can be seen a gain of $8.7 \%$ in time with prefabricated design items in relation to the global average (see Table 1). There was a decrease in the man-hours, including the items related to welding of industrial pipes, which resulted in a decrease in the assembly time of metallic structures. The methodology used to evaluate the time savings is obtained using Eqn (2):

$$
\text { Time save }(\%)=\frac{\sum\left(t_{F M I}-t_{E S}\right)}{\sum t_{F M I}} \times 100,
$$

where: $t_{F M I}$ - time required to perform the welds, considering a standard percentage of $35 \%$ prefabricated; $t_{E S}$ - time required to perform the welds, considering the percentage of prefabricated according to Figure 3.

It can be seen in Table 1 that the 3", 12" and 8"diameters, respectively, brought significant gains to the project. This can be credited the high quantity of pipes designed with these diameters in the pipe rack. However, the 4" pipes are the second largest quantity of welds in the design and their results indicate an increase in time, what can be attributed to their low number of prefabricated welds. One way of obtaining greater gains in this project would be to increase the amount of prefabricated welds of that diameter. Additionally further gains could be achieved by increasing the quantity of prefabricated pipes with diameters 6", 14" and 18", as these diameters have greater supply in the market for purchase, and are easier to transport and preassemble.

\section{Conclusions and future work}

This work proposed and applied the DOR Framework that explores the synergies between BIM and Lean principles to improve workflows, data analysis, and 3D visual management of construction planning and control. The proposed methodology has strong dependencies on standardizing and integrating engineering systems that are necessary to interdisciplinary management. These dependencies were the main barriers encountered to implement the Digital Obeya room. Throughout the empirical study, the challenges were overcome with the flexibility to offer and adapt these dependencies at the engineering management level. For a more widespread application of the proposed framework, it would be necessary to integrate a global standard of information interoperability (i.e. ISO16739 and ISO15926), and workflows to link engineering processes.

In this project, the implementation of the DOR Framework was promoted by means of regular meetings with the aid of a 3D model and involving experts to prevent future problems during the construction phase. Therefore, simulations were developed following the principles of constructability to generate sequential planning for each preassembled module. The synergy between different areas using the $3 \mathrm{D}$ model was important to plan and coordinate the mounting sequence. With that coordination, the welding-time was reduced in $8.7 \%$ related on global prefabrication average in construction projects from Fails Management Institute (FMI), according to Hoover et al. (2017).

This research fills an important gap in previous research by integrating BIM and Lean in the construction industry. As noted by other research works, the simultaneous adoption of these principles in construction can be 
a potential source of confusion. Despite indications of the possible benefits throughout a project's life cycle, typical approaches lack a consistent work methodology and usually focus on the design and planning phases only. The proposed Digital Obeya room formalizes a well-defined methodology that can guide the implementation of BIM and Lean from construction planning through work execution. This new framework acts as a solid basis for future conceptual research in BIM and Lean construction. From a practical point of view, the empirical study has demonstrated the quantitative gains that can be achieved by applying the proposed methodology. Results demonstrate an increase in predictability in construction planning, making the schedule more adherent to what is actually achieved in the field and improving the cooperation between stakeholders. Future work in this topic could investigate the following propositions: (1) case study to assess the compatibility between Lean and BIM principles amongst companies of different industries and others geographical locations; (2) measure with metrics the $\mathrm{CO} 2$ emissions between prefabs and currently approach.

\section{Acknowledegements}

The research is supported by the Brazilian Federal Agency for Support and Assessment of Post-graduate Education (CAPES).

\section{References}

Andersson, J.; Bellgran, M. 2009. Spatial design and communication for improved production performance, in Swedish Production Symposium, 2009, 1-8.

Arayici, Y.; Coates, P.; Koskela, L.; Kagioglou, M.; Usher, C.; O'Reilly, K. 2011. Technology adoption in the BIM implementation for Lean architecture practice, Automation in Construction 20: 189-195.

https://doi.org/10.1016/j.autcon.2010.09.016

Becerik-Gerber, B.; Rice, S. 2010. The perceived value of building information modeling in the US building industry, Journal of Information Technology in Construction 15: 185-201.

Blankenburg, D.; Kristensen, K.; Aasland, K. E.; Sivertsen, O. I. 2013. Virtual Obeya: collaborative tools and approaches to boost the use of simulators in concept design, in $27^{\text {th }}$ European Conference on Modelling and Simulation (ECMS), 2013, Ålesund, Norway. https://doi.org/10.7148/2013-0163

Bruch, J. 2012. Management of design information in the production system design process. Mälardalen University.

Childe, S. 2011. Case studies in operations management, Production Planning \& Control 22: 107-107. http://dx.doi.org/10.1080/09537287.2011.554736

Clemente, J.; Cachadinha, N. 2013. Bim-Lean synergies in the management on mep works in public facilities of intensive use - A case study, in $21^{\text {st }}$ Annual Conference of the International Group for Lean Construction (IGLC 21), 2013, $751-760$.

Construction Industry Institute. 1987. Constructability concepts file. $3^{\text {rd }} \mathrm{ed}$. Construction Industry Institute.

Construction Industry Institute. 1993. Constructability implementation guide. $34^{\text {rd }}$ ed. Construction Industry Institute.

Dave, B.; Kubler, S.; Pikas, E.; Holmström, J.; Singh, V.; Främling, K.; Koskela, L.; Peltokorp, A. 2015. Intelligent products: Shifting the production control logic in construction (with Lean and BIM), in $23^{\text {rdt }}$ Annual Conference of the International Group for Lean Construction (IGLC 23), 2015, 341-350.

Hamdi, O.; Leite, F. 2012. BIM and Lean interactions from the bim capability maturity model perspective: A case study, in Proceedings of the $20^{\text {th }}$ Annual Conference of the International Group for Lean Construction, 2012.

Hickethier, G.; Tommelein, I.; Hofmann, M. 2011. MDM as a tool for process improvement in building modeling, in The $13^{\text {th }}$ International DSM Conference, 2011, 349-362.

Hijazi, W.; Alkass, S.; Zayed, T. 2009. Constructability assessment using BIM/4D CAD simulation model, in AACE International Transactions, AACE, 1-14.

Hoover, S.; Trombitas, P.; Cowles, E. 2017. Prefabrication: The changing face of engineering and construction.

Ichikawa, H. 2009. Simulating an applied model to optimize cell production and parts supply (Mizusumashi) for laptop assembly, in Proceedings of Winter Simulation Conference, 2009, 2272-2280.

https://doi.org/10.1109/WSC.2009.5429193

Javadi, S.; Shahbazi, S.; Jackson, M. 2013. Supporting production system development through the Obeya concept, in IFIP Advances in Information and Communication Technology. Berlin: Springer, 653-660. https://doi.org/10.1007/978-3-642-40352-1_82

Jergeas, G.; Van Der Put, J. 2001. Benefits of constructability on construction projects, Journal of Construction Engineering and Management 127: 281-290.

https://doi.org/10.1061/(ASCE)0733-9364(2001)127:4(281)

Jupp, J. 2017. 4D BIM for environmental planning and management, Procedia Engineering 180: 190-201. https://doi.org/10.1016/j.proeng.2017.04.178

Kardec, A.; Simonsen, O. 2004. Relatório Final ABAST-02 Promover o Aumento da Produtividade das Empresas de Construção e Montagem com Vistas à Melhoria da Competitividade da Indústria Nacional.

Kifokeris, D.; Xenidis, Y. 2017. Constructability: Outline of past, present, and future research, Journal of Construction Engineering and Management 143(8). https://doi.org/10.1061/(ASCE)CO.1943-7862.0001331

Koskela, L. 1992. Application of the new production philosophy to construction. Technical Report No. 72. CIFE.

Lindlof, L.; Soderberg, B. 2011. Pros and cons of lean visual planning: experiences from four product development organisations, International Journal of Technology Intelligence and Planning 7(3): 269-279. https://doi.org/10.1504/IJTIP.2011.044614

Morgan, J. M.; Liker, J. K. 2006. The Toyota product development system: Integrating people, process and technology. $1^{\text {st }}$ ed. Productivity Press.

O'Connor, J. T.; Schulz, M. J.; Rusch, S. E. 1986. Constructability improvement during engineering and procurement. Construction Industry Institute.

O'Connor, J. T.; Rusch, S. E.; Schulz, M. J. 1987. Constructability concepts for engineering and procurement, Journal of Construction Engineering and Management 113: 235-248. https://doi.org/10.1061/(ASCE)07339364(1987)113:2(235)

Olatunji, O. A. 2011. Modelling the costs of corporate implementation of building information modelling, Journal of Financial Management of Property and Construction 16: 211-231. https://doi.org/10.1108/13664381111179206

Oosterwal, D. P. 2010. The Lean machine: How Harley-Davidson drove top-line growth and profitability with revolutionary lean product development. AMACOM. https://doi.org/10.1111/j.1540-5885.2012.00977.x

Othman, E.; Ahmed, A. 2011. Improving building performance through integrating constructability in the design process, 
Organization, Technology \& Management in Construction: An International Journal 3: 333-347.

https://doi.org/10.5592/otmcj.2011.2.6

Papadopoulos, N. A.; Sotelino, E. D.; Martha, L. F.; Nascimento, D. L. M.; Faria, P. S. 2017. Evaluation of integration between a BIM platform and a tool for structural analysis, Sist. Gestão 12: 108-116.

Rischmoller, L.; Alarcón, L. F.; Koskela, L. 2006. Improving value generation in the design process of industrial projects using CAVT, Journal of Management in Engineering 22: $52-60$. https://doi.org/10.1061/(ASCE)0742-597X(2006)22:2(52)

Runeson, P.; Host, M. 2009. Guidelines for conducting and reporting case study research in software engineering, Empirical Software Engineering 14(2): 131-164. https://doi.org/10.1007/s10664-008-9102-8

Russell, J.; Gugel, J.; Radtke, M. 1992. Benefits and costs of constructability: Four case studies. Construction Industry Institute, University of Texas at Austin.
Sacks, R.; Radosavljevic, M.; Barak, R. 2010. Requirements for building information modeling based lean production management systems for construction, Automation in Construction 19: 641-655. https://doi.org/10.1016/j.autcon.2010.02.010

Terenghi, F.; Cassina, J.; Kristensen, K.; Terzi, S. 2014. Virtual Obeya: A new collaborative web application for running lean management workshops, in 2014 International Conference on Engineering, Technology and Innovation: Engineering Responsible Innovation in Products and Services (ICE 2014), 2014. https://doi.org/10.1109/ICE.2014.6871554

Triviños, A. N. S. 1987. Introdução à pesquisa em ciências sociais: o positivismo, a fenomenologia, o marxismo. 1a. ed. São Paulo: Atlas.

Voss, C.; Tsikriktsis, N.; Frohlich, M. 2002. Case research in operations management, International Journal of Operations \& Production Management 22: 195-219. https://doi.org/10.1108/01443570210414329

Yin, R. K. 2004. Estudo de caso - planejamento e métodos. Daniel Grassi.

Daniel Luiz de Mattos NASCIMENTO. Is currently PhD Candidate in Civil and Environmental Engineering at PUC-Rio and Engineering Consultant at Tecgraf Institute / PUC-Rio since 2015. Master of Science in Industrial Construction (Mechanical Engineering) at Fluminense Federal University. Graduated in Production Engineering and Blackbelt in Six Sigma. Professor of MBA in Management for Total Quality and MBA in Strategic Management of Production and Maintenance of LATEC at the Fluminense Federal University. He also had worked at Petrobras in the Oil \& Gas sector for 10 years in production planning and control of the industrial construction. Currently, he works as a researcher and has scientific productions in the areas of Building Information Modeling (BIM), Multicriteria Methods, Industrial Plants Construction, Manufacturing, Operations Management, Sustainable Development, Sustainable Construction, Smart Cities, Industry 4.0 and Lean Systems.

Elisa SOTELINO. Is a Professor in the Department of Civil Engineering at PUC-Rio, Rio de Janeiro, Brazil. She received her $\mathrm{PhD}$ in Solid Mechanics from Brown University, USA. Prior to joining PUC-Rio, she was a Professor at Virginia Tech (2005-2011) and an Associate Professor at Purdue University (1990-2004), both in the USA. She was Associate Editor for the American Society of Civil Engineers (ASCE) Journal of Structural Engineering (1992-2009). She also chaired the ASCE Technical Committee on Emerging Computing Technology (1999-2003), and served as a member on the both the advisory board and the scientific committee for the European Community on Computational Methods and Applied Sciences Thematic conferences on Computational Methods in Structural Dynamics and Earthquake Engineering (2007 and 2009).

Thiago Pires Santoloni LARA. Is currently a Master's student in Civil Engineering, with an emphasis in structures at the Pontifical Catholic University of Rio de Janeiro (PUC-RJ); Thiago acts as a researcher in Tecgraf Institute / PUC-Rio in the areas of Building Information Modeling and Sustainability. His current research is on use of Building information models to perform diverse analysis throughout the life cycle of civil structures.

Rodrigo Goyannes Gusmão CAIADO. Is currently a $\mathrm{PhD}$ candidate in Sustainable Management Systems in Production Engineering Program, with an emphasis in the area of decision support in organizations at the Federal Fluminense University (UFF); Master in Civil Engineering with an emphasis in Construction Management and Graduated in Production Engineering from UFF. Mr. Caiado acts as a researcher and has scientific productions in the areas of Project Management, Multicriteria Methods, Sustainability, Lean manufacturing, and Building Information Modeling. In addition, Mr. Caiado holds an MBA in Business Management and has professional experience in projects in the Oil and Gas and Naval Construction sectors. His current research is on Operations Management, Process Improvement and Performance Measurement Systems, particularly in Lean Six Sigma Operations focusing on "the study of flows and processes and their impact on sustainability, eco-efficiency and green operations" and the Production Planning and Control process in Architecture, Engineering and Construction (AEC) projects, particularly lean construction.

Paulo IVSON. Is a PhD candidate in Computer Science with emphasis in Computer Graphics at the Pontifical Catholic University of Rio de Janeiro (PUC-Rio), Master in Computer Science with emphasis in Computer Graphics and Graduate in Computer Engineering at PUC-Rio. For the last 12 years, he has worked at Tecgraf Institute / PUC-Rio, where he coordinates several R\&D projects with partners in the Oil \& Gas, AEC/FM and Manufacturing industries. Mr. Ivson has scientific productions in the areas of Information Visualization, Real-Time Rendering, Computer-Aided Design, Building Information Modeling and Lean Production. His current research focuses on applying best concepts of Information Visualization to improve the effectiveness of 3D-based decision support systems for engineering. 